\title{
Hypersensitivity reaction in peri-oral skin associated with metal dental implants
}

\author{
Aruna Wimalarathna \\ Department of Prosthetic Dentistry, Faculty of Dental Sciences, University of Peradeniya, Sri Lanka
}

\begin{abstract}
This case study presents the rare entity of a hypersensitivity reaction in the perioral skin associated with metal dental implants. A 69-year-old male patient was treated with complete upper and lower implant-supported overdentures. The patient showed extra-oral blackish pigmentations on the skin of the entire neck region four months after placing the implants. This presentation appeared to be a suspected association of allergic reactions to metal dental implants in otherwise healthy individuals. Although titanium is considered a biocompatible metal for human surgical procedures, there are some instances in which patients can be allergic to titanium and other associated elements. Therefore, it would be better to perform a hypersensitivity reaction test before introducing metal devices to the patients. (JOURNAL OF DENTAL IMPLANT RESEARCH 2021;40(3):76-79)
\end{abstract}

Key Words: Dental implants, Titanium, Allergic reactions, Hypersensitivity, Pigmentations

\section{INTRODUCTION}

Allergic reactions can be ranged from a minor hypersensitivity reaction to deadly situations like anaphylactic shocks in the human body. In general, allergic reactions are a very common phenomenon and considers as benign, but the quality of life can decrease remarkably ${ }^{1)}$. In dentistry verities of metallic and organic materials are using and some of them have been reported to have pro-allergenic properties. The allergic symptoms from those materials are restricted not only the mouth but also found on extra-oral skin on various part of the body ${ }^{2)}$. Among them, Mercury, Nickel, Chromium, Palladium and Cobalt are known as classic allergens ${ }^{3)}$, while Titanium is considered as biocompatible material ${ }^{4)}$. The allergic contact dermatitis is considered as Type IV (Delayed Type) hypersensitivity rection in immunology.

Therefore, several products, which containing titanium are used more frequently during orthopaedic surgeries and dental implants. However, there were some reported evidence in literature allergic symptoms caused by titanium-based materials. Thomas et al. reported a case that developed eczema after titanium-based osteosynthesis ${ }^{5)}$. Facial eczema associated with a titanium dental implant was reported by Egusa et al. ${ }^{6}$. Furthermore, Siddiqi et al. revealed that titanium can induce hypersensitivity in susceptible patients, and could play a major role in implant failure $^{7)}$. However, the dental materials containing titanium are associated with allergic symptoms is still controversial.

In this case study, we presented a case scenario that seemed to be suspected association of allergic reactions to titanium dental implants with extra-oral blackish pigmentations.

\section{CASE REPORT}

A 69-year-old male patient who had twelve-year of experience in complete edentulousness and he requested some form of fixed prostheses in order to overcome his

Received June 27, 2021, Revised July 31, 2021, Accepted August 17, 2021. (c) Journal of Dental Implant Research.

This is an open access article distributed under the terms of the Creative Commons Attribution Non-Commercial License (http://creativecommons.org/licenses/by-nc/4.0) which permits unrestricted non-commercial use, distribution, and reproduction in any medium, provided the original work is properly cited.

Correspondence to: Aruna Wimalarathna, https://orcid.org/0000-0001-5265-3589

Department of Prosthetic Dentistry, Faculty of Dental Sciences, University of Peradeniya, Kandy 21000, Sri Lanka. Tel: +94-812387504, Fax: +94-812388948, E-mail: aaakwimalarathna@gmail.com 

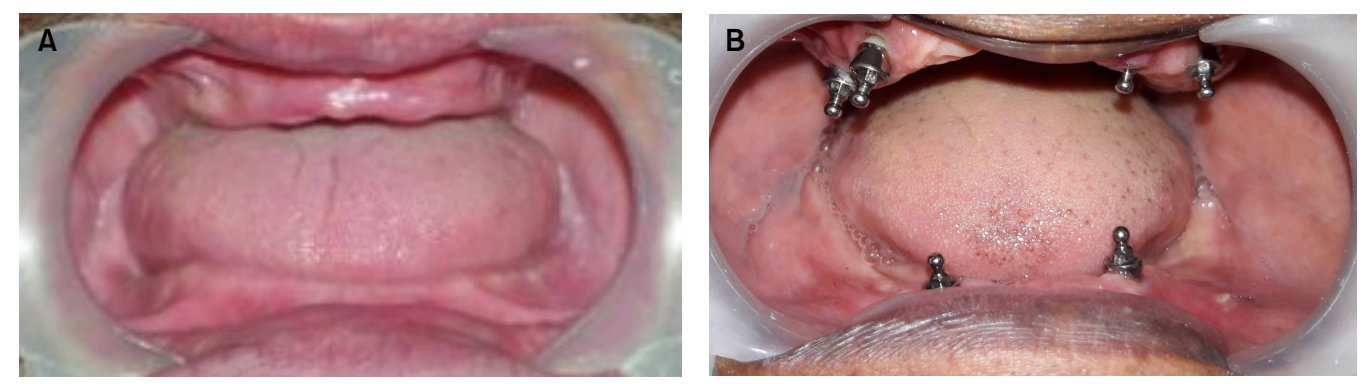

Fig. 1. Pre-op and post-op intra-oral photographs of patient's mouth.
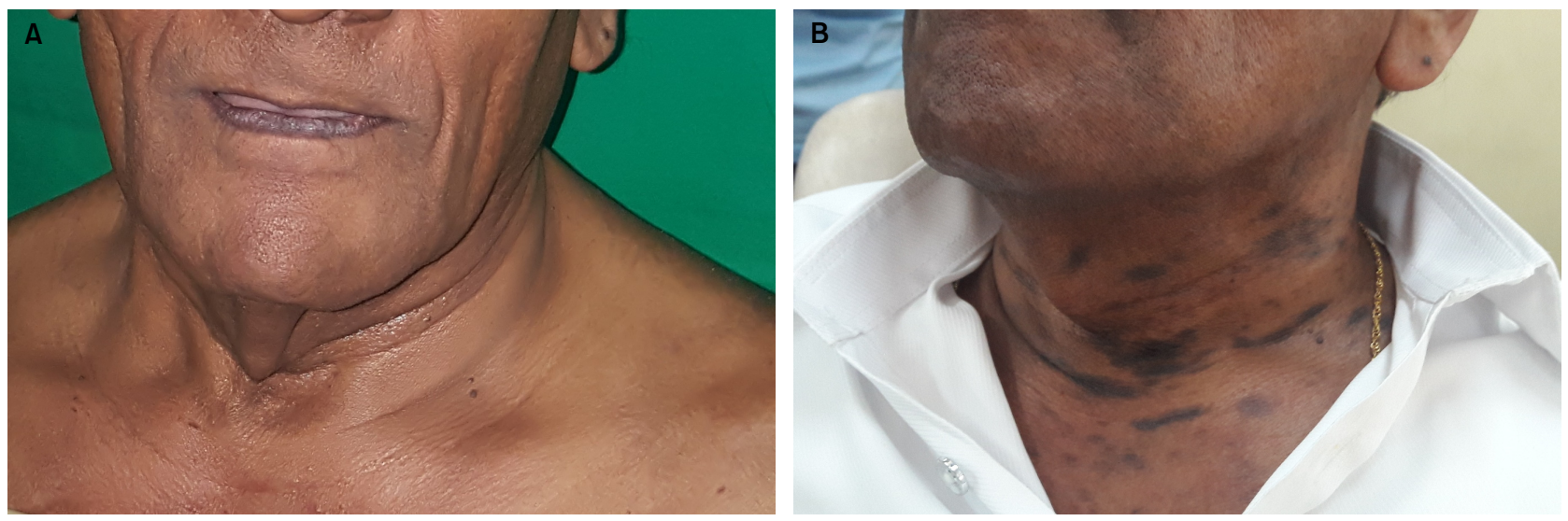

Fig. 2. Pre-op and post-op images of the skin of the patient's neck region.

concerns with existing removable prosthesis. Which were difficulty in mastication, poor retention and difficult to tolerate during a speech in an otherwise healthy individual. After performing a thorough clinical examination and radiological investigations, all the possible fixed options were given to him with explaining the pros and cons of each procedure. He was willing to proceed both upper and lower implant-supported complete overdentures. After getting consent from the patient, he underwent for implant surgery placement with the help of prefabricated surgical guide which made according to the Cone Beam Computed Tomography (CBCT) implant sites assessment (Fig. 1). Four NeucleOss T6 implants (4.1 $\mathrm{mm} \times 10.0 \mathrm{~mm}$ ) which made out of titanium Gr5 material were placed in the maxillary canine and first premolar osteotomy sites. Similarly, two implants from the same brand $(3.5 \mathrm{~mm} \times 10 \mathrm{~mm}$ ) were placed in relation to canine regions in the mandibular arch with a torque of $50 \mathrm{Ncm}$ for fixture and $4 \mathrm{Ncm}$ for the covering screws.

After achieving successful osseointegration of implants after three-months from their placement, the newly fab- ricated both upper and lower implant-supported overdentures were delivered to the patient. He was satisfied with the new set of complete dentures due to overcoming his previous problems.

After one month from denture delivery, he was noticed that there were some blackish patches appeared on the skin of his neck region. The patient was recalled immediately and clinical examination, denture examination and radiological investigations were done (Fig. 2). None of them was showing any abnormalities or evidence of implant complication such as peri-implantitis (Fig. 3). Pigmentation was spread towards the chest in about one-month duration and settled in same extensions and magnitude. The patient medical and dental records revealed that he did not take any type of medicine or dental treatments throughout in last six months except implant placement. Further, he did not have any known allergies for foods or acrylic dentures for the last twelve years of their using period.

The patient was not complaining any pain or discomfort from the pigmentation patches and he was not 

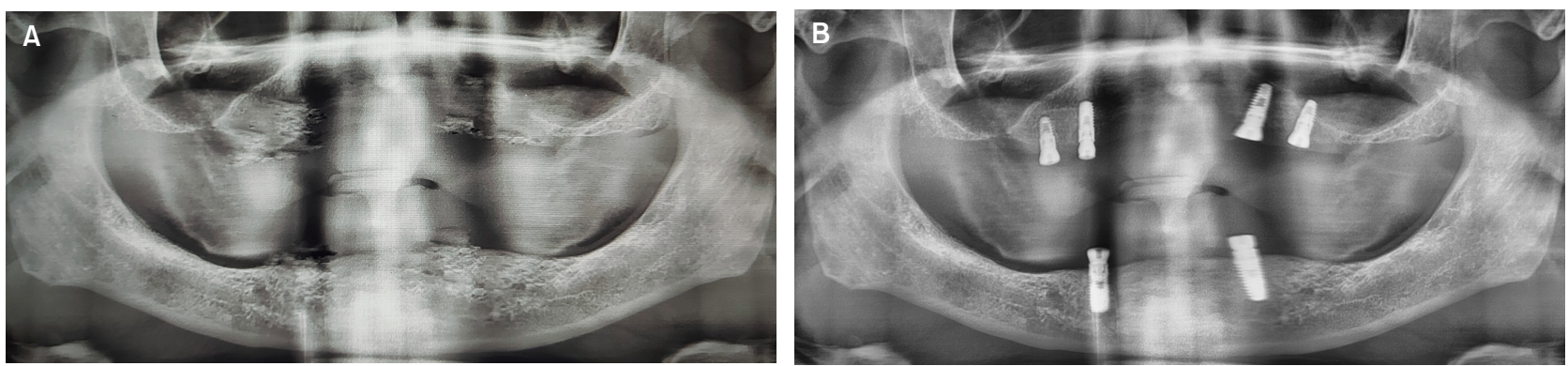

Fig. 3. The dental panoramic tomography of the patient, before treatments and six months after implant placement.

keen about aesthetics side especially due to most of the areas were covered by cloths. Anyway, the patient was referred to the dermatologist and got the opinion as there might be a hypersensitivity reaction for the dental implants. But the patient was not willing to undergo any investigations (such as blood investigations and patch tests) to rule out the allergen and he refused to retrieve the implants if the reports will reveal that titanium allergy. Then, the patient was kept under observation and agreed to do the regular review after every six-month. Ultimately, the condition was suspected as an association of extra-oral allergic reactions to metallic dental implants. The patient is still under reviewing and up-to-date there are no changes or complications.

\section{DISCUSSION}

Titanium was used as a material for dental implants manufacturing at a very beginning of dental implants development stage $^{8,9)}$. From the 1960s, titanium was developed as an acceptable and biocompatible material in order to use for human kinds in varies kind of medical, aesthetics and dental purposes. Widely used indications are including arthroplasty, osteo $\urcorner$ synthesis, pacemakers, oral reconstructive procedures, anchorage of bone conductive hearing aids and epistheses, jewelry for body piercing as well as dental implants ${ }^{5,6)}$. Since 1980s dental implants became one of the popular treatment modalities for replacement of missing teeth ${ }^{2}$. Even though comparatively titanium is far better than any other material to replace or stabilize the human body part, there was some reported evidence that has shown some complications such as hypersensitivity and rejections. Therefore, it should be emphasized that no material, including implants, can be con-sidered universally biocompatible $e^{5)}$.

Even, sometimes the allergic reactions like skin rash, flush, and eczema appeared after placement of implants due to any other reasons, there is a tendency to relate it to the implants whether it is not entirely related to titanium hypersensitivity ${ }^{6}$. Instead of pure titanium, mostly used alloys such as titanium, aluminium, and vanadium for construction of dental implants to increase their physical strength. However, the small amount of other elements associated with tita $\neg$ nium alloys can act as "impurities" that can be initiated allergic reactions in patients ${ }^{6)}$.

According to Harloff et al., study regarding various types of titanium alloys, such as sponge titanium, $\mathrm{TiAl}_{6} \mathrm{~V}_{4}$, and iodide titanium, they revealed that titanium alloys contained very small amounts of additional elements such as beryllium, cobalt, chromium, copper, iron, nickel, and palladium ${ }^{7)}$. In 2008, Forte et al. also emphasized that these elements might be the causative agents for a different form of allergic reactions in patients with dental implants ${ }^{10)}$. Similarly, Schuh et al. also reported that even a small amount of nickel in titanium alloys may provoke or intensify allergic reactions ${ }^{11)}$. Further, Matthew et al., showed that alloys like copper-beryllium and aluminium-beryllium alloys on guinea pigs caused delayed skin hypersensitivity reactions ${ }^{12}$.

There are some medical and dental studies have been reported in related to titanium allergy, and our case study also documented as a suspicious case of metal implant allergy. Among them, most of the studies have shown the allergic reactions appeared as contact dermatitis around titanium products ${ }^{13,14}$. In this case, the same acrylic denture material that has been used for the new set of dentures is similar to his previous dentures. In ad- 
dition, stainless-steel ball-abutments and metal housings with rubber O-rings have been used as retentive components for the overdentures. However, in our patient developed blackish pigmentations (dermatitis symptoms) on the general skin surface.

The management of dental implant hypersensitivities is still symptomatic. Getting dermatological and specialist medical opinions as well as undergoing necessary investigations according to the allergic symptoms are mandatory. Such as blood investigations and hypersensitivity tests like patch test. The retrieval of the well-functioning implants is controversial unless the hypersensitivity reactions seem to be lethal or life-threatening. Because, Osseointegrated dental implants when working well, the removal of such implants is not considered easy or risk-free procedure. If the decision was taken as osseointegrated implants to be removed, it is recommended to use an implant-retrieval tool to minimize the risks and to perform the less invasive effects in jawbones. Therefore, in this case, the patient is still under reviewing without retrieval of his implants.

\section{CONCLUSION}

Even though titanium considered as a biocompatible metal for using human surgical procedures, there are some instances which can be allergic for titanium and other associated elements. Therefore, it would be better to perform the hypersensitivity reaction test prior to introduce the metal devices for the patients.

\section{CONFLICT OF INTEREST}

The author is declared that there is no conflict of interests on any materials or products which were described in the manuscript.

\section{DATA AVAILABILTTY STATEMENT}

All the available information relevant to the case report has been included into the manuscript already.

\section{ORCID}

Aruna Wimalarathna,

https:/ / orcid.org/0000-0001-5265-3589

\section{REFERENCES}

1. Hosoki M, Nishigawa K, Miyamoto Y, Ohe G, Matsuka Y. Allergic contact dermatitis caused by titanium screws and dental implants. J Prosthodont Res 2016;60:213-9.

2. Hosoki M, Bando E, Asaoka K, Takeuchi H, Nishigawa K. Assessment of allergic hypersensitivity to dental materials. Biomed Mater Eng 2009;19:53-61.

3. Lundstrom IM. Allergy and corrosion of dental materials in patients with oral lichen planus. Int J Oral Surg 1984;13:16-24.

4. Garau V, Masala MG, Cortis MC, Pittau R. Contact stomatitis due to palladium in dental alloys: a clinical report. J Prosthet Dent 2005;93:318-20.

5. Williams DF. Titanium: epitome of biocompatibility or cause for concern. J Bone Joint Surg Br 1994;76:348-9.

6. Chaturvedi TP. Allergy related to dental implant and its clinical significance: review. Clinical, Cosmetic and Investigational Dentistry 2013;5:57-61.

7. Harloff T, Hönle W, Holzwarth U, Bader R, Yhomas P, Schuh A. Titanium allergy or not? "Impurity" of titanium implant materials. Health 2010;2:306-10.

8. Branemark PI, Adell R, Albrektsson T, Lekholm U, Lundkvist S, Rockler B. Osseointegrated titanium fixtures in the treatment of edentulousness. Biomaterials 1983;4:25-8.

9. Breine U, Branemark PI. Reconstruction of alveolar jaw bone. An experimental and clinical study of immediate and preformed autologous bone grafts in combination with osseointegrated implants. Scand J Plast Reconstr Surg 1980;14:23-48.

10. Forte G, Petrucci F, Bocca B. Metal allergens of growing significance: epidemiology, immunotoxicology, strategies for testing and prevention. Inflamm Allergy Drug Targets 2008; 7:145-62.

11. Schuh A, Thomas P, Kachler W, Göske J, Wagner L, Holzwarth $\mathrm{U}$, et al. Allergic potential of titanium implants. Orthopade 2005;34:327-8.

12. Matthew IR, Frame JW. Ultrastructural analysis of metal particles released from stainless steel and titanium miniplate components in an animal model. J Oral Maxillofac Surg 1998;56:45-50.

13. Thomas P, Bandl WD, Maier S, Summer B, Przybilla B. Hypersensitivity to titanium osteosynthesis with impaired fracture healing, eczema, and T-cell hyperresponsiveness in vitro: case report and review of the literature. Contact Dermat 2006;55:199-202.

14. Egusa H, Ko N, Shimazu T, Yatani H. Suspected association of an allergic reaction with titanium dental implants: a clinical report. J Prosthet Dent 2008;100:344-7. 